DOI: 10.12731/2658-6649-2019-11-5-101-106

УДК 612.017.1

\title{
СОСТОЯНИЕ Т-РЕГУЛЯТОРНОГО ЗВЕНА ИММУННОЙ СИСТЕМЫ У БОЛЬНЫХ РАКОМ ПОЧКИ
}

\author{
Мочев А.В., Беленюк В.Д., Гвоздев И.И.
}

Было проведено исследование фенотипического состава Т-регуляторных клеток периферической крови у больных раком почки. В результате, нами были обнаружены существенные изменения в системе адаптивного иммунитета, участвующие в противоопухолевом иммунном ответе. Было отмечено снижение на 17\% фракции лимфочитов, и увеличение популяиии моноцитов на 23\%. Обнаруженные изменения в пуле Т-клеток могут указывать на увеличение способности к миграџии в ткани для местной реализации своих функиий, также зафиксировано усиление супрессорной функиии регуляторных Т-клеток.

Ключевые слова: рак почки; регуляторные Т-клетки, проточная иุитометрия.

\section{STATE REGULATORY T MANAGEMENT OF THE IMMUNE SYSTEM IN PATIENTS WITH KIDNEY CANCER}

\author{
Moshev A.V., Belenyuk V.D., Gvozdev I.I.
}

A study was conducted on the phenotypic composition of peripheral blood T-regulatory cells in patients with kidney cancer. As a result, we found significant changes in the system of adaptive immunity involved in the antitumor immune response. A $17 \%$ decrease in the lymphocyte fraction was noted, and a $23 \%$ increase in the monocyte population. The detected changes in the T-cell pool may indicate an increase in the ability to migrate into the tissue for the local realization of their functions, as well as an increase in the suppressor function of regulatory T-cells.

Keywords: kidney cancer; regulatory T-cells, flow cytometry. 
Примерно 3\% всех злокачественных новообразований у взрослых приходиться на почечно-клеточный рак (ПКР), таким образом, это заболевание стоит в большинстве стран мира на десятом месте в структуре заболеваемости злокачественными опухолями [1]. В большинстве случаев ПКР диагностируется лишь на поздней стадии, как следствие у 40-50\% больных в течение первого года после лечения проявляются метастазы [2]. В период 2013-2015 гг. в РФ было зафиксировано более 25 тысяч больных ПКР, в возрасте около 60 лет, при этом смертность от ПКР достигла практически $30 \%$ [3]. Важнейшим компонентом противоопухолевого иммунного ответа является система адаптивного иммунитета. Регуляторные Т-клетки несмотря на малое количество, однако, выполняют крайне важную функцию, именно они сдерживают воспаление, которое часто приводит к локальному некрозу тканей. Основной функцией регуляторных Т-клеток является обратная селекция направленная на предотвращение аутоиммунной реакции путем ингибирования лимфоцитов несущих рецепторы к собственным тканям. Как следствие, чрезмерное увеличение активности регуляторных Т-клеток может сопровождаться ослаблением устойчивости к онкологическим и инфекционным заболеваниям, в тоже время недостаточность их функционирования приводит к повышению риска развития аутоиммунных заболеваний [4].

\section{Материалы и методы}

В исследовании приняли участие 81 больной ПКР, проходивших лечение на базе Красноярского краевого онкологического диспансера, в возрасте 40-55 лет. В качестве контрольной группы были обследованы 78 практически здоровых донора, аналогичного возрастного диапазона. Все исследования выполнены с информированного согласия испытуемых и «Правилами клинической практики в Российской Федерации», утвержденными Приказом Минздрава РФ от 19.06.2003 г. № 266. Иммунофенотипирование лимфоцитов проводили методом проточной цитометрии на приборе FC-500 Beckman Coulter (USA), с использованием готовых моноклональных антител Beckman Coulter (USA) [5]. Пробоподготовку осуществляли по стандартной методике [6].

\section{Результаты исследований}

В результате исследований, в периферической крови было зафиксировано изменение процентного соотношения основных популяций клеток 
иммунной системы. Наибольшим изменениям подверглись популяции непосредственно вовлеченные в патогенез ПКР. Фиксировалось снижение в 1,2 раза процента общих лимфоцитов, а так же повышение в 1,3 раза содержания общей популяции моноцитов, у больных ПКР относительно группы контроля. Обнаружено повышение процента Т-клеток (CD3+) в периферической крови больных ПКР. На фоне увеличения фракции CD3+-клеток, отмечалось снижение процента зрелых CD3+, готовых к миграции, что может указывать на снижение эффективности их функционирования и как следствие нарушение регуляции этого звена иммунной системы. В ходе исследования $\mathrm{CD} 3+\mathrm{CD} 4+-$-клеток отмечалось увеличение их процентного содержания, а также общего уровня зрелости. Подобное изменение указывает на повышение их роли в развитии патогенеза ПКР. При исследовании CD3+CD4+CD127+CD25+-клеток, как отдельной минорной субпопуляции $\mathrm{CD} 3+\mathrm{CD} 4+-$-клеток, так же отмечалась активация этой системы.

\section{Заключение}

Исходя из отмеченных изменений процентного содержания CD3+-клеток, можно заключить что, у больных ПКР отмечается нарушение активации и перераспределение Т-клеточного звена адаптивной иммунной системы. При онкологических заболеваниях, подобные нарушения существенно ухудшают возможности иммунной системы оказывать корректное сопротивление заболеванию, как следствие возможно осложнение течения болезни и ухудшение прогноза. Нарушение активации $\mathrm{CD} 3+$-клеток может быть частично связанно с увеличением содержания $\mathrm{CD} 3+\mathrm{CD} 4+\mathrm{CD} 127+\mathrm{CD} 25+$-клеток и более зрелой стадией их развития. $\mathrm{B}$ тоже время стоит отметить, что основные свои функция описанные популяции реализуют непосредственно в тканях, а следовательно изменение в периферической крови могут отображать ситуацию не в полной мере.

\section{Список литературы}

1. Аполихин О.И., Сивков А.В., Солнцева Т.В., Комарова В.А. Анализ урологической заболеваемости в Российской Федерации в 2005-2010 годах. // Экспериментальная и клиническая урология. 2012. № 2. С. 4-12

2. Каприна А.Д., Старинского В.В., Петровой Г.В. Злокачественные новообразования в России в 2013 году (заболеваемость и смертность). // М.: МНИОИ им. П.А. Герцена филиал ФГБУ «ФМИЦ им. П.А. Герцена» Минздрава России. 2015. 250 с. 
3. Писарева Л.Ф., Бояркина А. П., Одинцова И.Н., Гурина Л.И., Алексеева Г.Н. Эпидемиология рака почки в регионе Сибири и Дальнего Востока (1994-2008). // Урология. 2013. № 3. С. 52-56.

4. Кудрявцев И.В., Борисов А.Г., Кробинец И.И., Савченко А.А., Серебрякова М.К. Определение основных субпопуляций цитотоксических Т-лимфоцитов методом многоцветной проточной цитометрии // Медицинская иммунология. 2015. 6 (17). С. 525-538.

5. Савченко А.А., Модестов А.А., Мошев А.В., Тоначева О.Г., Борисов А.Г. Цитометрический анализ nk- и nkt-клеток у больных почечноклеточным раком. // Российский иммунологический журнал. 2014. Т. 8. № 4 (17). С. $1012-1018$.

6. Кудрявцев И.В., Борисов А.Г., Волков А.Е., Савченко А.А., Серебрякова М.К., Полевщиков А.В. Анализ уровня экспрессии CD56 и CD57 цитотоксическими Т-лимфоцитами различного уровня дифференцировки // Тихоокеанский медицинский журнал. 2015. № 2 (60). С. 30-35.

\section{References}

1. Apolihin O.I., Sivkov A.V., Solnceva T.V., Komarova V.A. Analiz urologicheskoj zabolevaemosti v Rossijskoj Federacii v 2005-2010 godah [Analysis of urological morbidity in the Russian Federation in 2005-2010]. Eksperimental'naya i klinicheskaya urologiya [Experimental and clinical urology]. 2012. № 2, pp. 4-12.

2. Kaprina A.D., Starinskogo V.V., Petrovoj G.V. Zlokachestvennye novoobrazovaniya v Rossii v 2013 godu (zabolevaemost' $i$ smertnost') [Malignant neoplasms in Russia in 2013 (morbidity and mortality)]. M.: FSBI "FIZI them. P.A. Herzen "Ministry of Health of Russia. 2015. 250 p.

3. Pisareva L.F., Boyarkina A.P., Odincova I.N., Gurina L.I., Alekseeva G.N. Epidemiologiya raka pochki v regione Sibiri i Dal'nego Vostoka (1994-2008) [Epidemiology of kidney cancer in the region of Siberia and the Far East (19942008)]. Urologiya [Urology]. 2013. № 3, pp. 52-56.

4. Kudryavcev I.V., Borisov A.G., Krobinec I.I., Savchenko A.A., Serebryakova M.K. Opredelenie osnovnyh subpopulyacij citotoksicheskih T-limfocitov metodom mnogocvetnoj protochnoj citometrii [Determination of the main subpopulations of cytotoxic T-lymphocytes using multicolor flow cytometry]. Medicinskaya immunologiya [Medical Immunology]. 2015. 6 (17), pp. 525-538.

5. Savchenko A.A., Modestov A.A., Moshev A.V., Tonacheva O.G., Borisov A.G. Citometricheskij analiz nk- i nkt-kletok u bol'nyh pochechnokletochnym rakom 
[Cytometric analysis of nk and nkt cells in patients with renal cell carcinoma]. Rossijskij immunologicheskij zhurnal [Russian immunological journal]. 2014. V. 8. № 4 (17), pp. 1012-1018.

6. Kudryavcev I.V., Borisov A.G., Volkov A.E., Savchenko A.A., Serebryakova M.K., Polevshchikov A.V. Analiz urovnya ekspressii CD56 i CD57 citotoksicheskimi T-limfocitami razlichnogo urovnya differencirovki [Polevshchikov A.V. Analysis of the expression level of CD56 and CD57 by cytotoxic T-lymphocytes of different levels of differentiation]. Tihookeanskij medicinskij zhurnal [Pacific Medical Journal]. 2015. № 2 (60), pp. 30-35.

\section{ДАННЫЕ ОБ АВТОРАХ}

Мошев Антон Викторович, м.н.с., лаборатория клеточно-молекулярной физиологии и патологии ФГБНУ Федеральньий исследовательский центр «Красноярский научныий иентр Сибирского отделения Российской академии наук», обособленное подразделение «НИИ медицинских проблем Севера» ул. П. Железняка, 3Г, г. Красноярск, 660022, Российская Федеращия kinger1@mail2000.ru

Беленюк Василий Дмитриевич, м.н.с., лаборатория клеточно-молекулярной физиологии и патологии ФГБНУ Федеральный исследовательский центр «Красноярский научный иентр Сибирского отделения Российской академии наук», обособленное подразделение «НИИ медицинских проблем Севера» ул. П. Железняка, 3Г, г. Красноярск, 660022, Российская Федеращия dyh.88@mail.ru

Гвоздев Иван Игоревич, м.н.с., лаборатория клеточно-молекулярной физиологии и патологии ФГБНУ Федеральный исследовательский иенттр «Красноярский научный иентр Сибирского отделения Российской академии наук», обособленное подразделение «НИИ медииинских проблем Севера» ул. П. Железняка, 3Г, г. Красноярск, 660022, Российская Федераџия Leshman-mult@mail.ru

\section{DATA ABOUT THE AUTHORS}

Moshev Anton Viktorovich, junior researcher, Laboratory of the Cellular Molecular Physiology and Pathology 
Federal Research Center "Krasnoyarsk Science Center» of the Siberian Branch of the Russian Academy of Sciences, Scientific Research Institute of medical problems of the North 3G, P. Geleznyaka str., Krasnoyarsk, 660022, Russian Federation kinger1@mail2000.ru

Belenyuk Vasily Dmitrievich, junior researcher, Laboratory of the Cellular Molecular Physiology and Pathology

Federal Research Center «Krasnoyarsk Science Center» of the Siberian Branch of the Russian Academy of Sciences, Scientific Research Institute of medical problems of the North 3G, P. Geleznyaka str., Krasnoyarsk, 660022, Russian Federation dyh.88@mail.ru

Gvozdev Ivan Igorevich, junior researcher, Laboratory of the Cellular Molecular Physiology and Pathology Federal Research Center «Krasnoyarsk Science Center» of the Siberian Branch of the Russian Academy of Sciences, Scientific Research Institute of medical problems of the North

3G, P. Geleznyaka str., Krasnoyarsk, 660022, Russian Federation Leshman-mult@mail.ru 